\title{
«Bulletin de la Société internationale des amis de Montaigne», Classiques Garnier, 2013, 1, n. 57
}

\section{Sabine Lardon}

\section{(2) OpenEdition}

1 Journals

\section{Édition électronique}

URL : http://journals.openedition.org/studifrancesi/1306

DOI : 10.4000/studifrancesi.1306

ISSN : 2421-5856

Éditeur

Rosenberg \& Sellier

\section{Édition imprimée}

Date de publication : 1 décembre 2015

Pagination : 582

ISSN : 0039-2944

\section{Référence électronique}

Sabine Lardon, « «Bulletin de la Société internationale des amis de Montaigne», Classiques Garnier, 2013, 1, n. 57 », Studi Francesi [En ligne], 177 (LIX | III) | 2015, mis en ligne le 01 décembre 2015, consulté le 07 janvier 2021. URL : http://journals.openedition.org/studifrancesi/1306 ; DOI : https:// doi.org/10.4000/studifrancesi. 1306

Ce document a été généré automatiquement le 7 janvier 2021.

\section{(c)}

Studi Francesi è distribuita con Licenza Creative Commons Attribuzione - Non commerciale - Non opere derivate 4.0 Internazionale. 


\title{
«Bulletin de la Société
} internationale des amis de Montaigne», Classiques Garnier, 2013, 1, n. 57

\author{
Sabine Lardon
}

\section{RÉFÉRENCE}

«Bulletin de la Société internationale des amis de Montaigne», Classiques Garnier, 2013, 1, n. 57, pp. 119.

1 Le bulletin s'ouvre sur un préambule d'Olivier GUERRIER (pp.11-12), sur un émouvant hommage d'André TOURNON à la regrettée Katherine Almquist qui nous a prématurément quittés (En souvenir de Katherine Almquist, pp.13-14) et sur le compte rendu du conseil d'administration du 6 juin 2013 de la SIAM (pp. 17-19).

2 Thomas BERNS (Puissances et faiblesses de l'opinion commune chez Montaigne, pp. 23-38) s'intéresse à la notion d'opinion commune chez Montaigne pour en dégager les tensions et les valeurs. Il montre ainsi sa négativité, sa vanité (vanité de régler sa vie sur la renommée et l'opinion commune), sa fausseté (son illusoire vérité), mais également la positivité et la simplicité des intuitions, la paradoxale utilité de l'illusion que constitue l'opinion commune, ainsi que son rôle pour l'histoire, la justice et la politique. Bérengère BASSET (Apophtegme et 'ordre du discours' dans les Essais de Montaigne. L'apophtegme entre pertinence et contingence, pp. 39-68) rappelle que l'apophtegme résulte de la rencontre fortuite entre une situation et un propos approprié. Sa «fossilisation» en «mot doré» tente de l'arracher au hasard, là où Montaigne cherche à l'inverse à rétablir sa contingence initiale par le réemploi qu'il en fait et sa réappropriation / «àpropriation» (entendue au sens d'une réappropriation de la parole d'autrui qui doit rester appropriée à la situation nouvelle pour laquelle elle est mobilisée). Alain LEGROS 
(Montaigne aux points, pp. 69-79) et ANDRÉ TOURNON ( Remarques préliminaires sur le double texte de l'édition de référence (Bompiani, Milan 2012)», pp. 81-99) s'intéressent à la ponctuation - ou plutôt à l'absence de ponctuation dans la pratique manuscrite de Montaigne qui préfère l'usage de la majuscule à celui du point comme signe de segmentation. Le volume se termine d'une part sur une note d'André GALLET (La "Mesnagerie" de 1600. Un réemploi de 1570-1572, pp. 101-103) qui revient, après le docteur J.-F. Payen et L. Feugère, sur l'édition de la Mesnagerie de Xénophon chez Claude Morel en 1600 pour évaluer la part de réimpression en la comparant aux deux leçons antérieures de 1571 et 1572 et en fournir la collation; d'autre part sur une présentation, par Edward TILSON (Prémices chatoyantes. Mireille Habert déchiffre la traduction par Montaigne des «sainctes imaginations» sebondiennes, pp. 105-119), de l'étude de Mireille Habert, Montaigne traducteur de la "Théologie naturelle" (Paris, Classiques Garnier, 2010) dont il dégage tout l'intérêt. 